\title{
Experimental Investigation of the Cooling Capacity of Gaseous Carbon Dioxide in Free Jet Expansion for Use in Portable Air-Cooling Systems
}

\author{
Chady Al Sayed, Ludwig Vinches, Stéphane Hallé \\ Department of Mechanical Engineering, École de Technologie Supérieure, Montreal, Canada \\ Email: chady.al-sayed.1@ens.etsmtl.ca
}

How to cite this paper: Al Sayed, C., Vinches, L. and Hallé, S. (2018) Experimental Investigation of the Cooling Capacity of Gaseous Carbon Dioxide in Free Jet Expansion for Use in Portable Air-Cooling Systems. Open Journal of Applied Sciences, 8 , 62-72.

https://doi.org/10.4236/ojapps.2018.82005

Received: January 6, 2018

Accepted: February 11, 2018

Published: February 14, 2018

Copyright $\odot 2018$ by authors and Scientific Research Publishing Inc. This work is licensed under the Creative Commons Attribution International License (CC BY 4.0).

http://creativecommons.org/licenses/by/4.0/

\begin{abstract}
This paper investigates the possibility of using the free expansion of gaseous $\mathrm{CO}_{2}$ in portable air-cooling systems. The cooling capacity of the gaseous $\mathrm{CO}_{2}$ free jet expansion was calculated using three different approaches and the results showed that the simplified calculations would give approximated cooling values with an $11.6 \%$ maximum error. The mass flow rate, upstream pressure and cooling capacity of the gaseous $\mathrm{CO}_{2}$ decreased with time. A maximum 48.5 watts of cooling was recorded at minute 4 and a minimum value of 10.4 watts at the end of the test. The drop in cooling capacity is due to the evaporation of the liquid $\mathrm{CO}_{2}$ inside the small cylinder which cools the two-phase $\mathrm{CO}_{2}$ mixture and causes a pressure drop (from $6 \mathrm{MPa}$ to $2.97 \mathrm{MPa}$ ), which also affects the mass flow rate of gaseous $\mathrm{CO}_{2}$ exiting the orifice (from $0.56 \mathrm{~g} / \mathrm{s}$ to $0.24 \mathrm{~g} / \mathrm{s}$ ). If this cooling technique is to be considered in portable compact-cooling systems, the mass, pressure and cooling capacity drop with time must be solved. One of the solutions could be to cover the cylinder with a heating coat to compensate for the heat absorbed by the evaporation of the liquid $\mathrm{CO}_{2}$.
\end{abstract}

\section{Keywords}

Gaseous $\mathrm{CO}_{2}$, Free Jet Expansion, Cooling Capacity, Compact Air-Cooling Technique

\section{Introduction}

Treating the ambient air is essential to many applications, for instance ensuring the thermal comfort of human beings, protecting against corrosion and conden- 
sation, and manufacturing certain electronic components [1]. Many techniques already exist to cool and dehumidify air, such as cooling coils, which circulate chilled water or refrigerants [2], liquid and solid-desiccant systems [3], and thermoelectric dehumidifiers [4]. All of the above techniques require the use of an additional external energy source, such as electricity, to heat the desiccant substance and regenerate its absorption capability, operate the thermoelectric module or to compress the refrigerants. Although many studies have been conducted using atmospheric discharge of carbon dioxide, to the best of our knowledge none have investigated the possibility of using free jet expansion as a technique to cool and dehumidify air. In 2012, Liu and Matsusaka [5] studied the characteristics of dry ice, such as particle size distributions and surface clearing capacity, when high-pressure liquid $\mathrm{CO}_{2}$ is released to atmospheric pressure. They found that the dry ice removal process is related to the jet temperature. The same year, Pursell [6] investigated the behavior of liquid $\mathrm{CO}_{2}$ release, that is, the jet temperature profile, expansion of liquid $\mathrm{CO}_{2}$ and sublimation of formed dry ice, to help validate models that can be used in risk assessment in case of accidental release of $\mathrm{CO}_{2}$. Researchers were also interested in studying the leakage of liquid $\mathrm{CO}_{2}$ from a facility [7] and its accidental release in pipelines during transportation [8].

When contained in pressurized cylinders, $\mathrm{CO}_{2}$ can usually exist in a gaseous state, two-phase fluid (saturated liquid and gaseous $\mathrm{CO}_{2}$ ) or supercritical fluid when the temperature and pressure of the $\mathrm{CO}_{2}$ exceed its critical point $\left(31^{\circ} \mathrm{C}\right.$ and 7.39 $\mathrm{MPa}$ ). This paper intends to study the possibility of using $\mathrm{CO}_{2}$ in a compact cooling system that is portable and easy to recharge, and which can lower the dry and wet bulb ambient temperature in one step. With this in mind, the cooling capacity of gaseous $\mathrm{CO}_{2}$ expansion into atmospheric pressure, released from small-pressurized cylinders containing a two-phase fluid $\mathrm{CO}_{2}$, will be investigated, calculated and compared with the experimental data using three approaches. The first uses air properties before and after $\mathrm{CO}_{2}$ injection without taking into consideration the amount of gaseous $\mathrm{CO}_{2}$ added to the final mixture, the second is based on the $\mathrm{CO}_{2}$ properties collected during the previous tests and the third uses the thermodynamic properties of the final mixture formed by air and $\mathrm{CO}_{2}$.

\section{Materials and Methods}

Three similar cylinders containing $2.3 \mathrm{~kg}$ each of pure saturated $\mathrm{CO}_{2}(99.99 \%)$ at $6 \mathrm{MPa}$ and $22^{\circ} \mathrm{C}$ are used for the tests. High pressure gaseous $\mathrm{CO}_{2}$ is brought to a $0.2 \mathrm{~mm}$ diameter expansion orifice, using an insulated flexible pigtail connected directly to the cylinder valve at one end and to a needle valve at the opposite end. The $\mathrm{CO}_{2}$ expansion will be used to cool a constant hot and humid airflow set to $37^{\circ} \mathrm{C} \pm 0.5^{\circ} \mathrm{C}$ (Dry bulb) and $69 \% \pm 1 \%$ relative humidity $(\mathrm{RH}$ ), which is highly similar to many extreme working environments such as excavations in deep mines. A pressure gauge with $\pm 1 \%$ accuracy and a high accuracy 
resistance temperature detector (RTD) with a dual element sensor, connected directly between the needle valve and the expansion orifice, measure and record the pressure and temperature of the gaseous $\mathrm{CO}_{2}$ before its expansion to atmospheric pressure.

Figure 1 shows a schematic of the experimental bench without the $\mathrm{CO}_{2}$ components. A microclimate chamber of $2 \mathrm{~m}^{3}$ is used to create an environment at constant temperature $\left(37^{\circ} \mathrm{C} \pm 0.5^{\circ} \mathrm{C}\right)$ and relative humidity $(69 \% \pm 1 \%)$. To create a stable environment within the microclimate chamber, a single humidifier and heating resistance are placed inside, controlled by a thermocouple and a humidity detector, using the LabVIEW [9] platform on a PC. The inlet of a DC blower is connected to the microclimate chamber using an insulated flexible hose, and its outlet is connected to a polymethyl methacrylate (PMMA) tube having an inside diameter of $5 \mathrm{~cm}$. The $\mathrm{CO}_{2}$ flow reducer (orifice) is connected to the PMMA tube $10 \mathrm{~cm}$ downstream from the outlet of the blower (see Figure 1). A flow meter (FLUKE 922) with a maximum uncertainty of $1 \%$ is used to measure the volumetric flow rate of the air inside the PMMA tube, prior to $\mathrm{CO}_{2}$ injection, at $80 \mathrm{~cm}$ apart from the flow reducer. The expansion of the $\mathrm{CO}_{2}$ will be used to cool a constant hot and humid airflow coming directly from the microclimate chamber. A thermocouple type J (TC1) is inserted within the insulated flexible hose $10 \mathrm{~cm}$ upstream from the inlet of the DC blower to measure and collect the temperature of the air before it has mixed with the $\mathrm{CO}_{2}$. A second thermocouple type J (TC2) is placed inside the PMMA tube, $50 \mathrm{~cm}$ from the blower outlet, where the flow would be fully developed (Reynolds number = 4500). It is used to measure the temperature of the air after it has mixed with the $\mathrm{CO}_{2}$. The PMMA tube is isolated by a semi flexible polyethylene foam rubber with a thermal resistance of $0.7044 \mathrm{~K} \cdot \mathrm{m}^{2} / \mathrm{W}$. The airflow supplied by the blower is set at $3 \mathrm{~L} / \mathrm{s}$ and is measured before every test.

To ensure statistically significant results, the test was triplicated. The duration

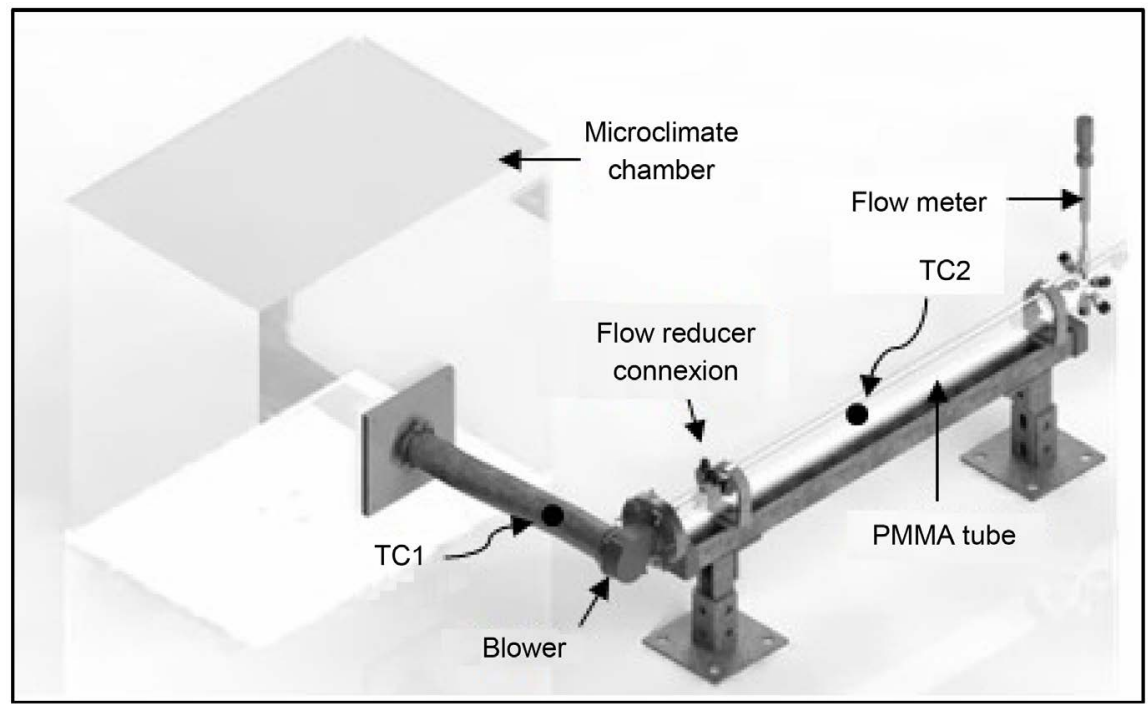

Figure 1. Schematic of the experimental bench without the $\mathrm{CO}_{2}$ components. 
of each test was set to 50 minutes, when theoretically, $75 \%$ of the $\mathrm{CO}_{2}$ mass inside the cylinder would have expanded into atmospheric pressure, if it is supposed that no pressure and temperature variations occur at stagnation state. The ratio $\left(r_{\text {critical }}\right)$ of absolute atmospheric pressure $\left(P_{a}\right)$ to absolute upstream pressure $\left(P_{u p}\right)$ will define the exiting condition of the gaseous $\mathrm{CO}_{2}$. In the case of $\mathrm{CO}_{2}$, the $r_{\text {critical }}$ is 0.547 . This leads to a critical absolute upstream pressure of $0.18 \mathrm{MPa}$ [7]. Beyond this absolute pressure, the flow will be chocked. For this study, the absolute upstream pressure was initially $6 \mathrm{MPa}$ and subsequent values never went lower than the critical value. Consequently, the flow rates of the $\mathrm{CO}_{2}$ injection were calculated theoretically by using Equation (1) for the mass flow rate calculation for choked flow [10].

$$
\dot{m}_{\text {choked }}=C A \sqrt{\kappa \rho P_{u p}\left(\frac{2}{\kappa+1}\right)^{\frac{\kappa+1}{\kappa-1}}}
$$

where $\dot{m}_{\text {choked }}$ is the mass flow rate of gaseous $\mathrm{CO}_{2}(\mathrm{~kg} / \mathrm{s})$; $\mathrm{C}$ the discharge coefficient of the orifice (dimensionless); A the orifice area $\left(\mathrm{m}^{2}\right) ; P_{u p}$ absolute pressure upstream; $\rho$ the gaseous $\mathrm{CO}_{2}$ density at upstream pressure and temperature $\left(\mathrm{kg} / \mathrm{m}^{3}\right)$ and $\kappa$ the dimensionless ratio of the heat capacity at constant pressure over the heat capacity at constant volume for the gaseous $\mathrm{CO}_{2}$ $(\kappa=1.29)$ [7].

The orifice's discharge coefficient $\mathrm{C}$ depends on the ratio of the orifice thickness $(e)$ and orifice diameter $(d)$. For a ratio $(e / d)$ between 1 to 7 , the discharged coefficient is considered to be constant $(C=0.81)$ [11], which is the case for the orifice used in this study $(e / d=5)$. The theoretical mass flow rates for the upstream pressure were compared to the mass flow rates determined experimentally by measuring the mass drop of the $\mathrm{CO}_{2}$ cylinder, using an electronic scale (Kilotech KWS 301) with a maximum capacity of $30 \mathrm{~kg} \pm 1 \mathrm{~g}$.

The cooling capacity of the gaseous $\mathrm{CO}_{2}$ free jet expansion will be calculated using three different approaches, where the first two are considered to be simplified.

\subsection{First Approach}

Due to the low mass injection of $\mathrm{CO}_{2}$, our first approach for calculating the cooling capacity will be to consider that the final state of the air is not affected by the amount of gaseous $\mathrm{CO}_{2}$ added. Using the information recorded for the air states before and after $\mathrm{CO}_{2}$ injection, we can calculate the cooling capacity received by the air using the energy conservation equation listed below:

$$
\dot{Q}_{\text {air }}=\dot{m}_{\text {air }} \times\left(h_{1}-h_{2}\right)-\dot{m}_{\text {removal }} \times h_{w}
$$

where $\dot{Q}_{\text {air }}$ is the cooling capacity received by the air from the injection of $\mathrm{CO}_{2}$; $\dot{m}_{\text {air }}$ is the mass flow of the air; $\dot{m}_{\text {removal }}$ is the mass flow of condensed water; $h_{1}$ and $h_{2}$ are the enthalpies of the air before and after being cooled respectively; $h_{w}$ is the enthalpy of condensed water at the dew point temperature (if condensation occurs). 


\subsection{Second Approach}

The second approach for calculating the cooling capacity of gaseous $\mathrm{CO}_{2}$ expansion requires that the state of the $\mathrm{CO}_{2}$ (pressure, temperature and enthalpy) be known before and after its expansion. The $\mathrm{CO}_{2}$ temperature just before expansion at orifice is recorded using a RTD probe and the pressure profile of the $\mathrm{CO}_{2}$ has already been collected (before expansion). A pressure-enthalpy diagram of the $\mathrm{CO}_{2}$ is used to approximate its temperature and enthalpy after expansion to atmospheric pressure, using the isenthalpic release approach of $\mathrm{CO}_{2}$ expansion [12] and then after cooling the air.

In the case of two-phase $\mathrm{CO}_{2}$ storage, the gaseous expansion to atmospheric pressure could cause some dry ice to form (less than $2 \%$ ) if the $\mathrm{CO}_{2}$ arriving to the orifice is always on its saturating curve and not superheated. In our case, the gaseous $\mathrm{CO}_{2}$ inside the cylinders was always colder than that which arrived to the expansion orifice, due to the heat dissipating from the cylinder valve, flexible pigtail, manometer and needle valve. Thus, the $\mathrm{CO}_{2}$ at the orifice was always at a slightly superheated state, and no dry ice was formed. Figure 2 shows the $\mathrm{CO}_{2}$ states inside the cylinder, at the orifice before expansion, after expansion and after cooling the air. The pressure-enthalpy diagram of the $\mathrm{CO}_{2}$ shown in Figure 2 [13] provides the enthalpies of the $\mathrm{CO}_{2}$ at every minute and in every state during the tests. Consequently, the cooling capacity of the $\mathrm{CO}_{2}$ expansion could be calculated using Equation (3) listed below.

$$
\dot{Q}_{\mathrm{CO}_{2}}=\dot{m}_{\mathrm{CO}_{2}} \times\left(h_{2}^{\prime}-h_{1}^{\prime}\right)
$$

where $\dot{Q}_{\mathrm{CO}_{2}}$ is the cooling capacity of the $\mathrm{CO}_{2}$ expansion; $\dot{m}_{\mathrm{CO}_{2}}$ is the mass

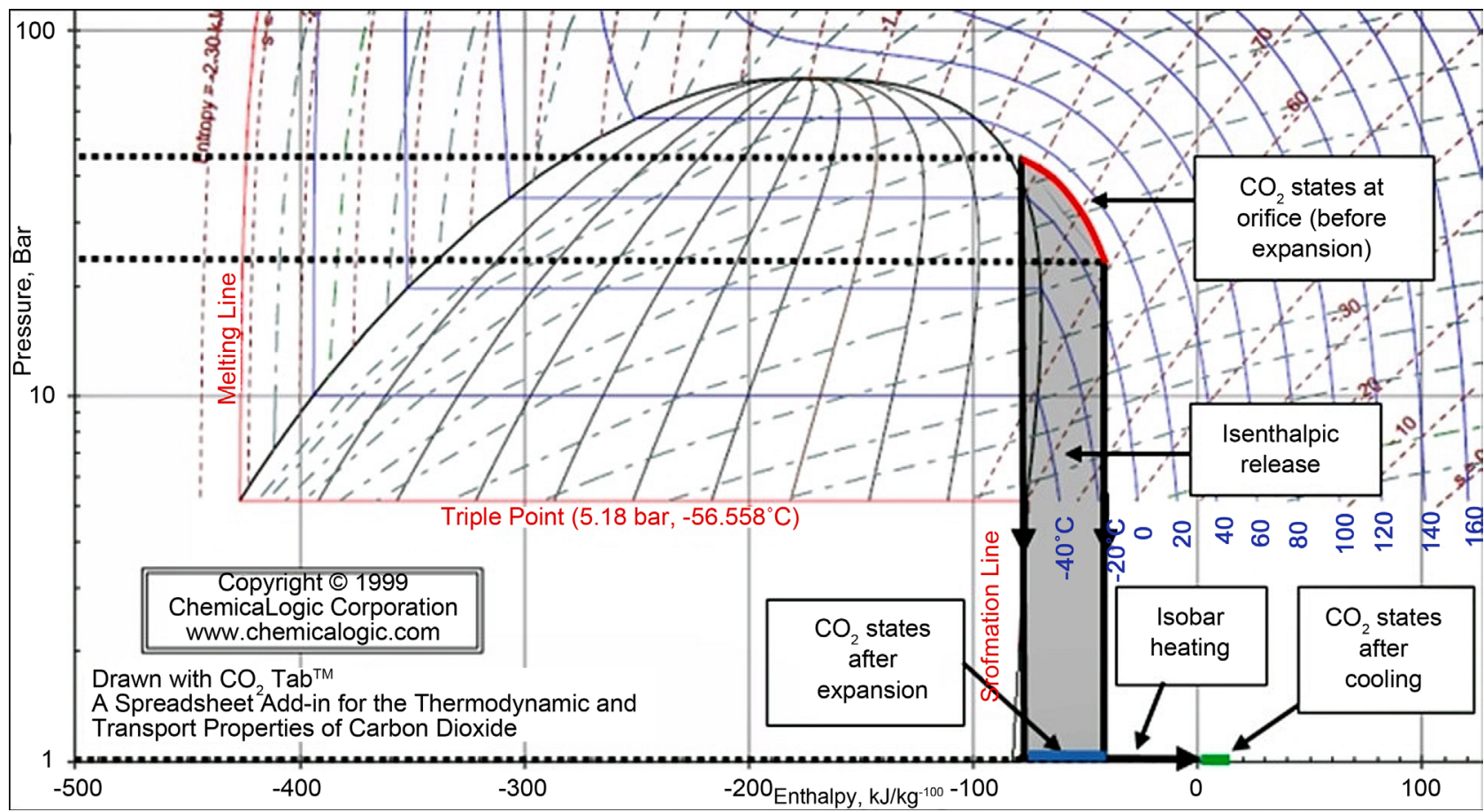

Figure 2. Pressure-Enthalpy diagram of $\mathrm{CO}_{2}[13]$. 
flow of gaseous $\mathrm{CO}_{2} ; h_{1}^{\prime}$ and $h_{2}^{\prime}$ are the enthalpies of the $\mathrm{CO}_{2}$ (at the same minute) after expansion and after cooling the air respectively.

\subsection{Third Approach}

For the final approach, the mass quantity of $\mathrm{CO}_{2}$ added into the stream of air is taken into consideration and the cooling capacity is calculated for the mixture formed from both air and $\mathrm{CO}_{2}$ flows. Furthermore, the air and the $\mathrm{CO}_{2}$ are considered to be perfect gases with negligible kinetic and potential energies. While the absolute humidity inside the final mixture of gases ( $\mathrm{air}+\mathrm{CO}_{2}$ ) is constant when no condensation occurs, the dew point of vapor is affected by its saturated pressure inside the final mixture of gases. By taking into consideration all the above, the third approach is considered to be more accurate for calculating the cooling capacity of the gaseous $\mathrm{CO}_{2}$ than the first two. For a stream of air at normal pressure, $37^{\circ} \mathrm{C}$ and $69 \% \mathrm{HR}$, the dew point temperature is $30.3^{\circ} \mathrm{C}$. When mixing the stream of air with a mass flow rate of gaseous $\mathrm{CO}_{2}$ ranging from 0.56 to $0 \mathrm{~g} / \mathrm{s}$, the dew point will start at a value of $29.3^{\circ} \mathrm{C}$ and increase in time to $30.3^{\circ} \mathrm{C}$. In this case, condensation will occur only if the value of the vapor pressure $\left(P_{\text {vapor }}\right)$, assumed to exist inside the mixture and calculated based on the following equations (Equations (4) and (5)), is greater than the vapor saturated pressure at mixture temperature.

$$
\begin{gathered}
P_{\text {vapor }}=P_{\text {total }} \times\left(\frac{\frac{m_{\text {vapor }}}{M_{\text {vapor }}}}{\frac{m_{\mathrm{CO}_{2}}}{M_{\mathrm{CO}_{2}}}+\frac{m_{\text {Dry air }}}{M_{\text {Dry air }}}+\frac{m_{\text {vapor }}}{M_{\text {vapor }}}}\right) \\
m_{\text {vapor }}=\frac{\omega}{m_{\text {Dry air }}}
\end{gathered}
$$

where $P_{\text {vapor }}$ is the vapor pressure assumed inside the mixture (in $\mathrm{kPa}$ ), $P_{\text {total }}$ is the atmospheric pressure $(101.3 \mathrm{kPa}) ; m_{\text {vapor }}, m_{\text {dry air }}$ and $m_{\mathrm{CO}_{2}}$ are respectively the mass of the vapor, the dry air and the $\mathrm{CO}_{2}$ present inside the mixture (in $\mathrm{kg}$ ); $M_{\mathrm{CO}_{2}}, M_{\text {dry air }}$ and $M_{\text {vapor }}$ are respectively the molar mass of the $\mathrm{CO}_{2}$, the dry air and the vapor (in $\mathrm{kg} \cdot \mathrm{mol}^{-1}$ ); $\omega$ the absolute humidity that existed in the air before mixing it with $\mathrm{CO}_{2}$ (in $\mathrm{kg}_{\text {vapor }} / \mathrm{kg}_{\text {dry air }}$ ). The cooling power of the mixture (air $+\mathrm{CO}_{2}$ ) will be calculated based on the following equations:

$$
\begin{gathered}
\dot{Q}_{m}=\dot{m}_{m} \times\left(h_{m 2}-h_{m 1}\right)-\dot{m}_{\text {removal }} \times h_{w} \\
h_{m}=\left(y_{\mathrm{CO}_{2}} \times C_{p \mathrm{CO}_{2}}+y_{\text {air }} \times C_{p \text { air }}\right) \times T+\left(h_{\mathrm{v} 0}+1.82 \times T\right) \\
\dot{m}_{m}=\dot{m}_{\text {air }}+\dot{m}_{\mathrm{CO}_{2}}
\end{gathered}
$$

where $\dot{Q}_{m}$ is the cooling capacity; $\dot{m}_{\mathrm{CO}_{2}}$ is the mass flow of gaseous $\mathrm{CO}_{2} ; h_{m 1}$ and $h_{m 2}$ are respectively the enthalpies of the mixture before and after $\mathrm{CO}_{2}$ cooling; $C_{p \mathrm{CO}_{2}}$ and $C_{p \text { air }}$ are the specific heat capacities at constant pressure for the gaseous $\mathrm{CO}_{2}$ and the air respectively; $h_{v 0}$ is the enthalpy of saturated 
vapor at $0^{\circ} \mathrm{C} ; y_{\mathrm{CO}_{2}}$ and $y_{\text {air }}$ are respectively the molar fraction of gaseous $\mathrm{CO}_{2}$ and air present inside the mixture; and $\mathrm{T}$ is the temperature of the mixture.

\section{Results and Discussion}

During all three tests, data were collected at each second and then averaged for each minute. Figure 3 shows the variation of the $\mathrm{CO}_{2}$ pressure inside the cylinders. The two-phase fluid $\mathrm{CO}_{2}$ inside the cylinder was originally at $6 \mathrm{MPa}$ and $22^{\circ} \mathrm{C}$. When the gaseous $\mathrm{CO}_{2}$ was released to cool the air, the same amount of liquid $\mathrm{CO}_{2}$ evaporated inside the cylinder to maintain the equilibrium. The latent heat absorption of the evaporated quantity of liquid $\mathrm{CO}_{2}(140.33 \mathrm{~kJ} / \mathrm{kg}$ at 6 $\mathrm{MPa}$ and $22^{\circ} \mathrm{C}$ ) cooled the $\mathrm{CO}_{2}$ inside the cylinders and directly affected its saturation pressure. This is showed in Figure 3, where at minute 1, the pressure of the $\mathrm{CO}_{2}$ inside the cylinder was at $6 \mathrm{MPa}$ and then dropped to $2.97 \mathrm{MPa}$, a $50.5 \%$ loss in initial stagnation pressure.

The mass flow of the $\mathrm{CO}_{2}$ exiting the orifice was also measured and calculated, using Equation (1) described above. The results are presented in Figure 4. A high similarity is apparent between the measured and calculated values. Because the mass flow exiting the orifice is in direct correlation with the $\mathrm{CO}_{2}$ pressure before expansion, the mass flow rate of the gaseous $\mathrm{CO}_{2}$ decreased with time. Its maximum value occurred at minute $1(0.56 \mathrm{~g} / \mathrm{s})$ where the pressure was at its

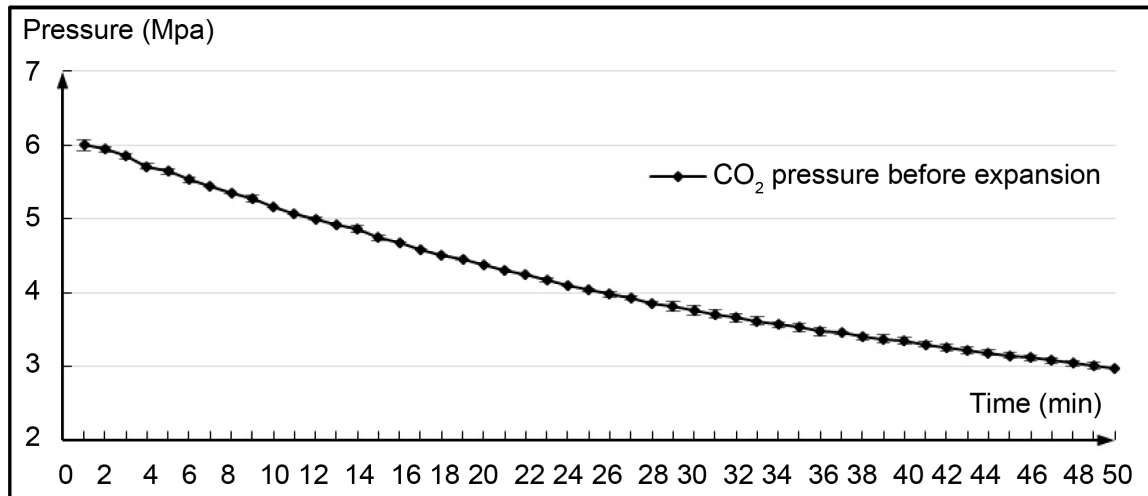

Figure 3. $\mathrm{CO}_{2}$ pressure profile.

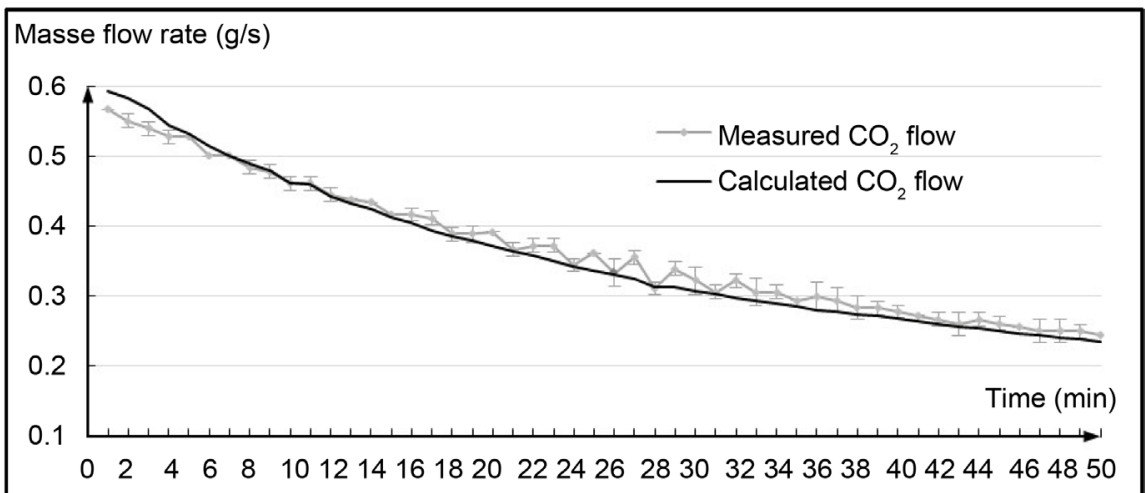

Figure 4. $\mathrm{CO}_{2}$ mass flows. 
peak and reached the lowest value at minute $50(0.24 \mathrm{~g} / \mathrm{s})$, which accounts for a $57 \%$ decrease.

For thermodynamic calculations, the temperature of the air before and after injecting the gaseous $\mathrm{CO}_{2}$ had also been recorded, along with the $\mathrm{CO}_{2}$ temperatures before expansion, at the orifice. The results are presented in Figure 5. The air before $\mathrm{CO}_{2}$ injection was at $37^{\circ} \mathrm{C}$ and $69 \%$ relative humidity. It reached its lowest temperature, after $\mathrm{CO}_{2}$ injection, at minute $4\left(28.7^{\circ} \mathrm{C}\right)$ and then started to rise until minute $50\left(33.9^{\circ} \mathrm{C}\right)$. The average $\mathrm{CO}_{2}$ temperatures, measured just before the expansion at orifice and by using an RTD, ranged between $21^{\circ} \mathrm{C}$ and $23^{\circ} \mathrm{C}$ during tests, while the surrounding environment was at $23^{\circ} \mathrm{C} \pm 1^{\circ} \mathrm{C}$.

While the volume flow rate of the air was set to $3 \mathrm{~L} / \mathrm{s}$, the $\mathrm{CO}_{2}$ had an average volume flow rate, calculated based on its measured mass flow rates during the tests, of $0.18 \mathrm{~L} / \mathrm{s}$. This last value is worth only $5.66 \%$ of the total volume flow rate of the mixing gases (air $+\mathrm{CO}_{2}$ ).

The cooling capacities of the gaseous $\mathrm{CO}_{2}$ expansion are calculated starting from minute 4 where the lowest temperature of the air was reached. The results are shown in Figure 6 where the first three minutes are not taken into consideration because the supply line already contained air at ambient temperature before the cylinder was opened, which would result in a mixture of air and $\mathrm{CO}_{2}$ inside the supply line and a decrease in the cooling efficiency of the $\mathrm{CO}_{2}$ expansion

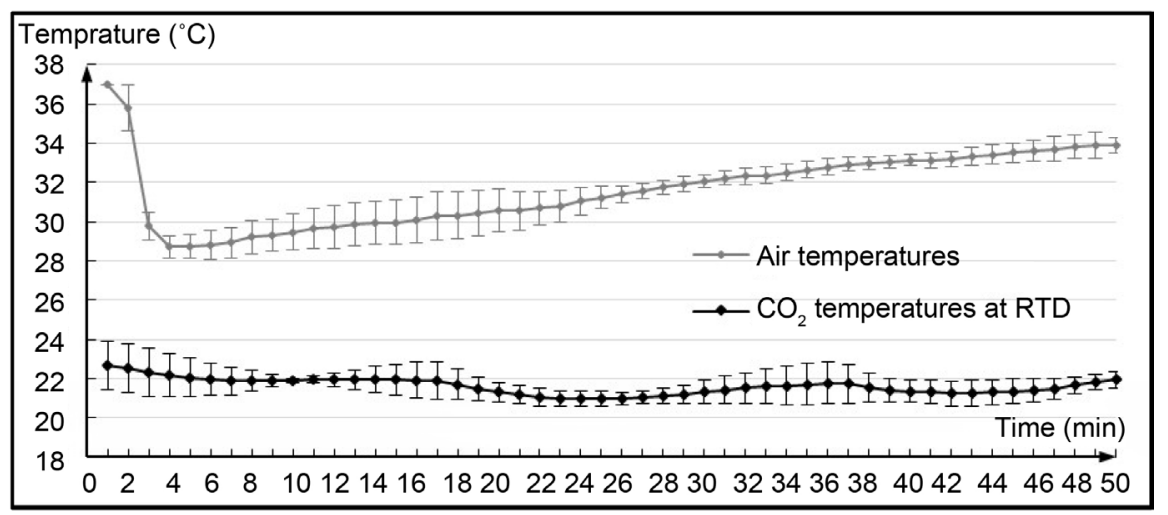

Figure 5. Temperature profiles for air and $\mathrm{CO}_{2}$.

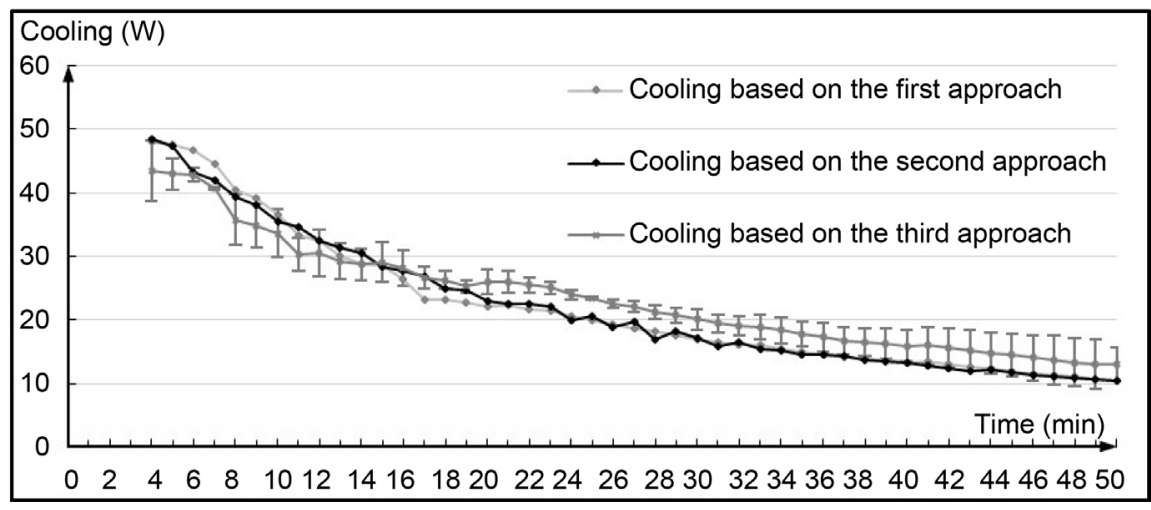

Figure 6. Cooling capacities of gaseous $\mathrm{CO}_{2}$ expansion. 
through the orifice.

As the pressure of the $\mathrm{CO}_{2}$ inside the cylinder drops and the mass flow rate exiting the orifice decreases, the cooling capacity of the $\mathrm{CO}_{2}$ expansion drops too, which. Based on the cooling capacity of the $\mathrm{CO}_{2}$ expansion using the air properties (first approach), we found a maximum cooling of $48 \mathrm{~W}$ at minute 4 and a minimum at the end of the test at $10.5 \mathrm{~W}$. This represents a $78.1 \%$ drop in cooling capacity. Similarly, if we consider the cooling capacity calculated based on the $\mathrm{CO}_{2}$ (second approach) and mixture properties (third approach), we find respectively a $78.7 \%$ drop (from $48.5 \mathrm{~W}$ to $10.3 \mathrm{~W}$ ) and a $70.1 \%$ drop (from 43.5 $\mathrm{W}$ to $13 \mathrm{~W}$ ). At minute 17 , condensation starts (dew point $=30.3^{\circ} \mathrm{C}$ ) in the case of the cooling capacity based on the first approach. The transition state from cooling where condensation occurs to non-condensation cooling is shown in the graphic by the big change of the curve's slope at dew point. Because calculations were made based on averaged values with one-minute intervals, the cooling capacity at this transition point has the biggest deviation $(3.8 \mathrm{~W})$ compared to the cooling capacities calculated based on the second approach (at a given point). In the case of the cooling capacity based on the third approach, the dew point had a variable value, due to the variable mass flow of gaseous $\mathrm{CO}_{2}$. At minute 4 , the dew point was at $28.7^{\circ} \mathrm{C}$ and it increased with the decrease of $\mathrm{CO}_{2}$ mass injected until reaching a value of $30.25^{\circ} \mathrm{C}$ at the end of the test (minute 50). The cooling capacity curve based on the third approach presented in Figure 6 shows the average values calculated for the three tests, along with their standard deviations. Because the mass flow rate of the $\mathrm{CO}_{2}$ at a given minute during any test was never exactly the same as for the other two tests (see standard deviations in Figure 4), the dew points and the transition from condensation to non-condensation states varied for each test. That is why a maximum deviation of $4.7 \mathrm{~W}$ from the average value can be seen at minute 4 . The highest cooling difference calculated between the three approaches was $5 \mathrm{~W}$ and occurred between the calculated value based on the second and third approach (11.6\% difference). For future work, the first two simplified approaches can be used for calculating the approximate cooling capacity if an $11.6 \%$ of maximum percentage error is allowed and a low percentage of gaseous $\mathrm{CO}_{2}$ is injected into the air stream $(\leq 5.66 \%$ of the total mixture).

\section{Conclusion}

The cooling capacity of gaseous carbon dioxide free jet expansion, released from a small cylinder containing a two-phase fluid, was experimentally studied to ascertain whether it could be used in a compact and easily rechargeable portable air-cooling system. Three approaches are used and compared for calculating the cooling capacity of the expanded gaseous $\mathrm{CO}_{2}$. Results indicate that the use of simplified calculation methods (first and second approach) gives approximated values with an $11.6 \%$ maximum percentage error, compared to the cooling capacity calculated based on the mixture's properties (third approach). The gaseous $\mathrm{CO}_{2}$ 
at the orifice was at its superheated state due to heat absorption that occurred between the cylinder valve and the expansion orifice. Because the $\mathrm{CO}_{2}$ volume inside the cylinder was relatively small and the evaporation of liquid $\mathrm{CO}_{2}$ into gaseous state highly affected the temperature of the two-phase fluid. The cooling of the two-phase $\mathrm{CO}_{2}$ decreased the pressure inside the cylinder and affected the mass flow rate of the gaseous $\mathrm{CO}_{2}$ exiting the orifice. Because the mass flow rate of gaseous $\mathrm{CO}_{2}$ is in direct relation with its upstream pressure, the cooling capacity of the free expansion gaseous $\mathrm{CO}_{2}$ decreased with time. The instability of the cooling capacity would be unsuitable for a portable cooling system. However, certain modifications could be made to resolve this while using small cylinders, such as maintaining the temperature of the two-phase fluid constant by covering the cylinder with a heating coat and compensating for the heat absorbed by the evaporation of the liquid $\mathrm{CO}_{2}$.

\section{Acknowledgements}

The authors would like to acknowledge the support of the Fonds de Recherche du Québec-Nature et Technologies (FRQNT) for its financial contribution to this study.

\section{Conflict of Interest}

The authors declare that they have no conflict of interest.

\section{References}

[1] ASHRAE (2001) Handbook Fundamentals. American Society of Heating, Refrigerating and Air Conditioning Engineers, Atlanta, 111.

[2] Gatley, D.P. (2000) Dehumidification Enhancements for 100-Percent-Outside-Air AHUs. Heating/ Piping/ Air Conditioning Engineering, 72, 51-59.

[3] Harriman, L. (2003) 20 Years of Commercial Desiccant Systems. Where They've Been, Where They Are, and Where They're Going. Heating/ Piping/Air Conditioning Engineering, 75, 43-44.

[4] Hsieh, C.S. (1994) Portable Thermoelectric Dehumidifier. Google Patents.

[5] Liu, Y.H. and Matsusaka, S. (2012) Characteristics of Dry Ice Particles Produced by Expanding Liquid Carbon Dioxide and its Application for Surface Cleaning. Advanced Materials Research, 508, 38-42.

[6] Pursell, M. (2012) Experimental Investigation of High Pressure Liquid $\mathrm{CO}_{2}$ Release Behaviour. Hazards Symposium Series No. 158, 164-171.

[7] Mazzoldi, A., Hill, T. and Colls, J.J. (2008) $\mathrm{CO}_{2}$ Transportation for Carbon Capture and Storage: Sublimation of Carbon Dioxide from a Dry Ice Bank. International Journal of Greenhouse Gas Control, 2, 210-218. https://doi.org/10.1016/S1750-5836(07)00118-1

[8] Pham, L.H.H.P. and Rusli, R. (2016) A Review of Experimental and Modelling Methods for Accidental Release Behaviour of High-Pressurised $\mathrm{CO}_{2}$ Pipelines at Atmospheric Environment. Process Safety and Environmental Protection, 104, 48-84. https://doi.org/10.1016/j.psep.2016.08.013

[9] National-Instruments-Corporation. 
http://www.ni.com/fr-ca/shop/labview/buy-labview.html

[10] Perry, R.H. and Green, D.W. (1999) Perry's Chemical Engineers' Handbook. McGraw-Hill Professional.

[11] Ward-Smith, A. (1979) Critical Flowmetering: The Characteristics of Cylindrical Nozzles with Sharp Upstream Edges. International Journal of Heat and Fluid Flow, 1, 123-132. https://doi.org/10.1016/0142-727X(79)90028-6

[12] Hebrard, J., Antoine, F. and Lacome, J.-M. (2011) Assessment of the Models for the Estimation of the $\mathrm{CO}_{2}$ Releases Toxic Effects. 12 th International Conference on Multiphase Flow in Industrial Plants (MFIP 12), Ischia, 21 September 2011. https://hal-ineris.archives-ouvertes.fr/ineris-00973629

[13] ChemicaLogic-Corporation.

http://www.chemicalogic.com/Documents/co2_mollier_chart_met.pdf 